\title{
O Cuidado com a Vida num Grupo Educativo de Pessoas Hipertensas e Diabéticas
}

\author{
Cristhian Antônio Brezolin, ${ }^{1}$ Enéas Rangel Teixeira, ${ }^{2}$ Jorge Luiz Lima da Silva, ${ }^{2}$ \\ Donizete Vago Daher, ${ }^{2}$ Jaqueline Ferreira, ${ }^{3}$ Clémence Dellaire ${ }^{4}$
}

\begin{abstract}
RESUMO
O objetivo deste estudo é conhecer e discutir as concepções dos usuários hipertensos e diabéticos sobre a repercussão do grupo educativo no cuidado com a vida. Estudo descritivo com abordagem qualitativa. O cenário do estudo foi numa Policlínica Regional, no município de Niterói, RJ, em um grupo de adultos e idosos com hipertensão arterial e Diabetes Mellitus. A coleta de dados foi efetuada por meio de entrevistas semiestruturadas com 12 usuários, realizadas entre dezembro de 2018 e fevereiro de 2019. A técnica de análise foi de conteúdo tipo temática. O perfil sociodemográfico dos entrevistados aponta predominância da faixa etária de 60 a 70 anos (42\%), em sua maioria do sexo feminino (58\%), aposentados (75\%) e casados (50\%). Os resultados foram analisados e organizados nas seguintes categorias temáticas: grupo como promotor de vivências; grupo como formulador e mantenedor de relações com o serviço de saúde e grupo como promotor do autocuidado. Conclui-se que as concepções dos usuários evidenciam que a atividade no grupo em saúde repercute positivamente no bem-estar do usuário, melhora a socialização, integrando o indivíduo ao serviço de saúde. Por conseguinte, facilita o acesso aos serviços prestados, bem como estimula a corresponsabilidade no contexto do cuidado com a vida diante do lidar com as doenças crônicas. Enfim, o grupo apresenta repercussões relevantes na ampliação e na emancipação no cuidado com a vida, que se exerce de modo dialogado e interativo numa atividade de educação em saúde.

Palavras-chave: Hipertensão. Diabetes mellitus. Educação em saúde. Saúde pública. Atenção primária à saúde. Cuidados de enfermagem.

\section{CARING FOR LIFE IN AN EDUCATIONAL GROUP OF HYPERTENSIVE AND DIABETIC PEOPLE}

ABSTRACT

The objective of this study is to know and discuss the conceptions of hypertensive and diabetic users about the repercussion of the educative group on life care. Descriptive study with qualitative approach. The study scenario was in Regional Polyclinic, in the city of Niterói, RJ, in a group of adults and elderly with hypertension and diabetes mellitus. Data collection was performed through semi-structured interviews with 12 users, conducted between December 2018 and February 2019. The analysis technique was thematic content. The sociodemographic profile of the interviewees indicates a predominance of the age group from 60 to 70 years $(42 \%)$, mostly female $(58 \%)$, retired $(75 \%)$ and married $(50 \%)$.The results were analyzed and organized into the following thematic categories: group as promoter of experiences; group as formulator and maintainer of relations with the health service; group as a self-care promoter. It is concluded that the users' conceptions show that the activity in the health group has a positive impact on the user's well-being, improves socialization, integrates it with the health service. Therefore, it facilitates access to the services provided, as well as stimulating co-responsibility in the context of life care in dealing with chronic diseases. Finally, the group has relevant repercussions on the expansion and emancipation in life care, which is exercised in a dialogic and interactive way in a health education activity.
\end{abstract}

Keywords: Hypertension. Diabetes mellitus. Health education. Public health. Primary health care. Nursing care.

RECEBIDO EM: 13/1/2020

MODIFICAÇÕES SOLICITADAS EM: 2/7/2020

ACEITO EM: 14/7/2020

\footnotetext{
${ }^{1}$ Autor correspondente. Universidade Federal Fluminense (UFF). Rua Dr. Celestino 74 - Centro/ Niterói - RJ, Brasil. CEP 24020-091. http://lattes.cnpq. br/9440711776788784. https://orcid.org/0000-0002-9525-2459. cristhian.brezolin@gmail.com

2 Universidade Federal Fluminense (UFF/RJ) - Niterói/RJ, Brasil.

3 Universidade Federal do Rio de Janeiro - Rio de Janeiro/RJ, Brasil.

${ }^{4}$ Faculté des Sciences Infirmières. Université Laval. Québec, Canadá.
} 


\section{INTRODUÇÃO}

O processo de educar em saúde é caracterizado pela posição ativa por parte de seus protagonistas, sejam estes os usuários, que constituem potenciais educandos, ou ainda os profissionais de saúde na condição de educadores, em um processo que tem por base o conhecimento em saúde e atitude sensibilizadora a respeito de seus direitos e responsabilidades, com aspectos intrínsecos a sua saúde e condições de vida (GERHARDT et al., 2016).

No acompanhamento de pessoas com Hipertensão Arterial Sistêmica (HAS) e Diabetes Mellitus (DM) o papel do profissional de saúde surge por meio das práticas de promoção à saúde e prevenção de Doenças Crônicas Não Transmissíveis (DCNT). Nesse grupo incluem-se condições patológicas crônicas com possibilidade de resultarem em complicações quando não manejadas adequadamente. Diversas atividades de educação em saúde emergem nesse meio, as quais precisam abordar situações de interesse e trabalhar com os usuários de modo personalizado e compreensivo (DUARTE et al., 2015).

$\mathrm{Na}$ abordagem ao sujeito com enfoque na educação em saúde almeja-se o cuidado com a vida considerado nesse estudo como emancipatório e que inclui o cuidado de modo geral, as vivências do cotidiano, o autocuidado e o estilo de vida (COLLIÈRE, 2003). O cuidado com a vida envolve a dimensão sociocultural, a subjetividade, o meio ambiente e os saberes populares e científicos, os quais no processo de interação humana e educativa estão em evidência.

O modelo teórico de Dorothea Orem trata do autocuidado como conjunto de ações intencionadas que o indivíduo realiza em seu contexto cultural e biológico, visando a lidar com fatores externos e internos implicados com a vida. A autora fala do cuidado universal, que é abrangente, e dos cuidados específicos da enfermagem, que requerem competência técnica científica e ética profissional (OREM, 2001).

O estilo de vida abrange um conjunto de hábitos e costumes que são influenciados, modificados, encorajados ou inibidos pelo prolongado processo de socialização. Busca-se, assim, que o usuário tenha um estilo de vida capaz de lidar com condições de saúde e doença, sem perder a sua qualidade de vida (MADEIRA et al., 2018).

O trabalho com grupos na atenção primária lida com essas dimensões, pois favorece a qualidade de vida dos participantes, nas dimensões física, mental e social. A troca de saberes entre participantes, o bem-estar proporcionado pelas atividades educativas e as orientações gerais recebidas são preconizadas como pontos cruciais nesse âmbito (ARANTES et al., 2015). Nesse contexto, quando se trata de ações voltadas para o cuidado com a vida, não se restringe somente à questão técnica e científica, mas às diferentes dimensões do sujeito, que merecem ser ouvidas.

Isso posto, as ações educativas, quando desenvolvidas na Atenção Primária à Saúde (APS), podem ser utilizadas pelos profissionais da área para ampliar as maneiras de promover saúde na medida em que se articula com a comunidade, mediante a interação participativa que visa à reflexão crítica da realidade (GERHARDT et al., 2016).

A importância de ações de cunho educativo e preventivo é abordada nas políticas de saúde, que trazem entre as atribuições do enfermeiro e da equipe de saúde a realização de atividades em grupo, nas Unidades Básicas de Saúde (UBS). Dessa forma, o processo educativo em saúde deve ser desenvolvido, buscando novas perspectivas de cuidar (BRASIL, 2012).

Assim, a educação em saúde contemporânea está ancorada no empoderamento, protagonismo e na gestão conjunta como ferramentas que permitam alcançar melhores condições de vida e bem-estar para as pessoas (STREHLOW et al., 2016). Destarte, é preciso conhecer por meio do próprio processo participativo como essas ações emancipatórias na educação em saúde repercutem na vida dos usuários.

De modo correlato, vale destacar que o grupo investigado nesse estudo é denominado "Bem vividos", no qual a tônica do cuidado com a vida é sempre enfatizada em conjunto com as orientações técnicas e científicas.

Diante dessas considerações iniciais faz-se o seguinte questionamento: Quais a concepções dos usuários hipertensos e diabéticos sobre a repercussão das atividades de grupo educativo no cuidado com a vida, em termos de saúde? Para responder a essa questão foi elaborado o seguinte objetivo: Conhecer e discutir as concepções dos usuários hipertensos e diabéticos sobre a repercussão do grupo educativo no cuidado com a vida.

\section{MATERIAIS E MÉTODOS}

Trata-se de estudo qualitativo descritivo que abarca as atividades de saúde em grupo, enfocando as equipes de cuidado em saúde voltadas aos usuários com hipertensão arterial e Diabetes Mellitus. Desse modo, os sujeitos da pesquisa foram os usuários participantes do grupo de hipertensos e diabéticos de uma Policlínica Regional no município de Niterói, RJ. 
Os critérios de inclusão foram: indivíduo adulto; maior de 18 anos de idade; idoso com 60 anos ou mais; que frequentava o grupo semanalmente por um período superior a seis meses. Como critérios de exclusão: membros com inserção no grupo inferior a seis meses e pessoas acometidas de transtornos mentais ou déficits cognitivos diagnosticados.

A coleta adotada foi feita por meio da técnica da entrevista semiestruturada, iniciada em dezembro de 2018 e finalizada em fevereiro de 2019. As entrevistas foram gravadas em dispositivo digital e posteriormente transcritas na íntegra. Cada entrevista durou em média 45 minutos, totalizando 8 horas e 36 minutos.

A análise dos dados foi realizada mediante análise de conteúdo tipo temática, de acordo com Laurence Bardin. As etapas seguidas para a análise de dados foram: pré-análise, caracterizada pela leitura de todo o material obtido; a exploração do material, de forma a selecionar as unidades de análise e a interpretação, que consiste no processo de categorização e subcategorização (BARDIN, 2011). Três categorias emergiram no estudo, a partir do agrupamento de subcategorias, segundo suas proximidades: 1 - grupo como promotor da vida; 2 - grupo como formulador e mantenedor de relações com o serviço de saúde; 3 - grupo como promotor do autocuidado.

A pesquisa foi desenvolvida atendendo aos aspectos éticos. O Termo de Consentimento Livre e Esclarecido foi assinado em duas vias pelo participante, ficando uma em posse do pesquisador e outra com ele. Destaca-se a confidencialidade da pesquisa: dessa forma, os nomes foram identificados pela letra " $E$ " em referência a palavra "entrevistado", seguida de número arábico conforme ordem de realização das entrevistas. A pesquisa foi aprovada pelo Comitê de Ética do Hospital Universitário Antônio Pedro, sob o parecer 2.183.825, atendendo à Resolução no 466/2012 do Conselho Nacional de Saúde.

\section{RESULTADOS}

No total foram entrevistados 12 participantes, destes 2 tinham Diabetes Mellitus, 4 apresentavam hipertensão arterial e 6 ambas as doenças. A predominância dos depoentes era do sexo feminino (58\%), com maioria na faixa etária de 60 anos ou mais (75\%), com cor da pele parda (50\%), com renda predominante de um a três salários mínimos (50\%) e com Ensino Médio completo (50\%).

Em relação à cor da pele autorreferida, observa-se que os participantes declararam-se pardos (50\%), negros (42\%) e brancos (8\%). O grau de esco- laridade médio dos entrevistados foi o Ensino Médio completo (50\%), porém houve ainda número significativo de participantes com o Ensino Superior completo $(17 \%)$, e ainda aqueles que frequentaram apenas o Ensino Fundamental, seja este completo (18\%) ou incompleto (15\%). Acerca da ocupação, observou-se que 9 entrevistados (75\%) eram aposentados, havendo ainda registro de uma cozinheira, uma servente e um desempregado.

\section{Grupo como promotor de vivências}

Entende-se como promoção de vivências o conjunto de mudanças que o indivíduo percebe em sua dimensão existencial e que impactam de forma positiva seu viver cotidiano (COLLIÈRE, 1999).

Promover vivências também é empoderar o participante em relação à superação dos seus próprios desafios e medos. Nesse sentido, evidencia-se que o grupo cria espaço propício para que o sujeito aperfeiçoe suas capacidades relacionais, melhorando assim sua autoestima e percepção do seu papel social, conforme constatado nas falas a seguir:

Coisas que eu sou meio difícil de me abrir, no meio deles eu consigo. Eu achava que não ia conseguir me prontificar para nada e eu me surpreendi porque eu me "acheguei". Isso é a liberdade que os profissionais dão e também as pessoas que participam desse grupo, a gente ganha incentivo dos outros e acaba se incentivando, a gente perde a vergonha, perde aquela inibição de quando a gente chega (E10).

Me sinto à vontade. Todo mundo respeita, não tem problema. (...) Eu quase não falava, eu sou muito tímido, ai com as reuniões eu até passei falar em público. Eles chamam, pedem para dar alguma opinião e eu acabo falando. Bastante eu não estou falando ainda, mas melhorei bastante (E3).

Destaca-se ainda na fala dos participantes o papel das atividades lúdicas desenvolvidas no grupo e a participação no grupo, como recurso de bem-estar psicológico que permite ao participante administrar situações conflituosas, problemas do cotidiano, bem como permite a reelaboração de sentimentos. Essas afirmativas podem ser constatadas nos seguintes depoimentos:

Eu venho aqui, mesmo que eu fique 2 horas ou 3 horas você esquece os problemas lá de fora, não tem coisa melhor. A gente esquece um pouquinho os problemas que todo mundo tem (E7). 
Por exemplo, digamos que você saiu de casa aborrecida $X$, voltando $X$ você chegando em casa vai ter aquele mesmo problema. Aí quando você sai de casa e vem aqui, aí quando você volta para casa, não volta $X$, volta $Y$, e já tem uma nova noção de como resolver aquele problema. Porque você chegou aqui, você riu, você brincou, você se divertiu com outras pessoas, bateu papo. $\mathrm{Na}$ quele momento ali o seu problema ficou em casa. (E8).

Então o bom desse grupo é que se a gente chega com um problema, a gente consegue esquecer daquele problema, a gente consegue se alegrar (E10).

(...) quando você entra num grupo que tem dança, tem ginástica, tem passeio, tem diversão, isso entra no seu organismo como se fosse remédio, como se diz, libera maior número de endorfina, essas coisas assim boas para o organismo. Então acho que isso faz bem para todos (E12).

\section{Grupo como formulador e mantenedor de relações com o serviço de saúde}

O serviço de saúde abrange no seu dia a dia uma gama de ações, como marcação de consultas, encaminhamento e realização de exames, consultas com especialistas, dispensação de medicação, entre outros. As falas descritas a seguir endossam essas afirmações:

É fundamental eu ser do grupo. Se eu sentir alguma coisa eles vão arrumar médico para mim, eles fazem esforço, eles mandam para outro lugar. Fora do grupo é uma dificuldade danada. Eu considero esse grupo como se você tivesse plano de saúde, porque no plano de saúde você vai e tem a médica que você quer marcar, às vezes demora até mais do que nós aqui. A coordenação do grupo leva até eles que esse é um participante do grupo, então você passa a ter tratamento diferenciado (E2).

Agora pelo menos a gente não tem que correr atrás de médico, aqui tem a enfermeira mesmo que marca para a gente quando precisa. Se você precisa de médico o posto está ali, mas você tem que ficar na fila esperando, esperando e esperando, até chegar sua vez e isso complica pra caramba (E7).

(...) a assistência médica que a gente recebe através do grupo fica mais fácil, porque a enfermeira aqui, ela sempre fala: pessoal quem está precisando da podóloga? Vou marcar! Quem está precisando de médico? Vou marcar! (E8).
É muito bom, muito bom. Gosto muito porque ajuda a gente, né? Tanto na parte médica que a gente precisa eles facilitam consulta médica para a gente (E4).

A realização de exames mais complexos, de consultas com especialistas, além do encaminhamento quando a unidade não consegue prover ao atendimento também foram apontados pelos usuários como fatores positivos da participação no grupo.

Aqui também tem marcação de consultas, isso facilita, a marcação de consultas é ótima, quando não tem na unidade eles mandam para outra e a outra aceita. Se eu não participasse do grupo ia ser mais difícil, pois eu não ia saber onde fazer a consulta, eles já avisam tudo (E6).

Essa ajuda deles se a pessoa participar do grupo, e ter essa ajuda para ser atendida, a gente tem preferência, até fui fazer um Doppler, elas perguntaram ao pessoal do grupo quem precisava fazer Doppler, aproveitei e fiz da perna. Até hoje vou tentar falar com a enfermeira, se ela consegue agilidade nessa consulta para mim (E11).

\section{Grupo como promotor do autocuidado}

O autocuidado como função humana reguladora é desempenhada pelo sujeito ou por alguém que execute por ele, visando à preservação da vida, da saúde, do desenvolvimento e do bem-estar. Quando é consciente, controlada, intencional e efetiva, atingindo a autonomia, a atividade é denominada "atividade de autocuidado" (OLIVEIRA et al., 2018).

Nessa perspectiva, a repercussão do grupo no autocuidado aparece nos seguintes aspectos desse estudo: nos hábitos alimentares, na dimensão multiprofissional, no lidar com a doença crônica, nas atividades físicas e na aquisição de possibilidades de autonomia para a vida cotidiana.

A adoção de hábitos alimentares adequados para suas condições crônicas é tema recorrente na fala dos entrevistados quando refletem sobre o aprendizado obtido no grupo. As falas a seguir ressaltam esse aspecto:

Tem uma receitinha assim: o que eu posso comer sem medo, o que posso comer moderado e o que posso comer esporadicamente. Eu não sou proibida de comer nada, eu tenho que saber dosar. Eu posso misturar arroz, feijão, batata, macarrão? Não posso. Aprendi aqui, a nutricionista que ensina tudo, e também ela falou que eu posso comer de tudo, só não posso exagerar, e outra 
coisa, não sou proibida de comer nada, só comer moderadamente e não posso pular refeição nenhuma (E5).

(...) eu procuro, se estou no meio de muita coisa doce, eu fico ali no meio, eu sei que eu posso comer um pedacinho, que não vai me prejudicar. Mas eu sei que se eu começar a comer o segundo, terceiro, aí já vai me prejudicar (E10).

Constata-se o entendimento dos entrevistados sobre a importância da reeducação alimentar e sua aplicação no cotidiano, visando ao manejo de sua condição crônica. Nota-se que as falas abordam hábitos alimentares presentes antes, ou seja, foram modificados por conta do que foi aprendido no grupo:

Olha, incorporei hábitos principalmente na alimentação. Pois tem alimentação que tem umas coisas que não são boas mesmo, se você come aquilo vai fazer açúcar no seu sangue. Caldo de cana eu adorava, gosto ainda, mas não tomo (E6).

A nutricionista ensina como comer, então eu fui fazer uma reeducação alimentar, eu aprendi uma reeducação alimentar aqui no grupo com as palestras dela, pelo que ela fala e com as receitinhas e saladinhas e outras coisas. A gente come de tudo, mas tudo light (E5).

Destaca-se ainda em relação à promoção do autocuidado o caráter multiprofissional do grupo, no qual todos os profissionais desempenham papel relevante nas orientações sobre o cuidar de si próprio, assim sensibilizando os participantes. Nesse sentido, o contato com a podóloga integrante da equipe emergiu com destaque, na fala dos participantes, o que demonstra a importância dessa modalidade de orientação especializada:

Às vezes a podóloga vem. Há poucos dias ela veio dar uma palestra e disse: gente, vocês que são diabéticos não procurem fazer o trabalho da podóloga. Ou seja, ficar cutucando a unha, cortando a unha de qualquer jeito. Se não dá para esperar chegar no dia da podóloga não tem problema, tem alguma coisa que está incomodando? Apara só aquela coisinha que está incomodando, não cortar onde não deve (E8).

E a podóloga ensina várias coisas para a gente que eu nem sabia, eu sabia que eu tinha que ter cuidado com os pés por causa da diabetes (...), mas tem muita coisa que eu não sabia que aprendi mesmo com a palestra da podóloga. Eu já desconfiava, mas com a palestra dela foi crucial (E5).
Você já foi na podóloga? Nós temos podóloga. Só trato meus pés na podóloga (E2).

A aceitação da enfermidade crônica também foi aspecto evidenciado nas falas dos entrevistados, o que denota relação com o autocuidado. As falas a seguir endossam essa afirmação:

(...) sobre diabetes, você tem que fazer uma opção, tratar e aproveitar, você tem que aproveitar a vida, mas tratar a doença também, vamos jogar $50 \%$ para cada e respeitar a doença, nesse momento que eu dei a trompada e arrebentei meu pé todo, agora vai ser $90 \%$ para diabetes $e$ o resto para mim. Você tem que ser esperto se a sua glicemia tiver alta toda a hora a cura vai demorar mais, você vai sofrer mais, elas passam muito isso para nós (E2).

(...) o que eu tenho aprendido é que diante da enfermidade a gente precisa lutar contra ela, porque a saúde é muito importante, a gente pode ter a enfermidade, mas não pode deixá-la tomar conta da gente a ponto de tirar nossa alegria e liberdade de viver (E10).

Na visão dos entrevistados que possuem hipertensão arterial, destaca-se o papel do grupo no satisfatório controle pressórico, na medida em que incorporando o procedimento de aferição nas atividades educativas o indivíduo sente-se mais seguro no seu dia a dia. Por conseguinte, o usuário torna-se mais consciente, de que qualquer alteração será constatada pelos profissionais.

A pressão está direitinha, desde que entrei no grupo eu nunca deixei de ver a pressão, tem que sempre verificar a pressão, até hoje está direitinho. Geralmente é 120/80,130, eles verificam lá na ginástica. Eu verifico assim às vezes quando vou ao médico, e agora verifico duas vezes na semana através do grupo (E11).

Agora minha pressão é $120 / 80$ no máximo 130/100. O grupo tem participação nisso, pois elas controlam. Elas controlam a pressão da gente. Toda vez que a gente vai fazer ginástica tem que verificar a pressão. Elas estão lá (E5).

Constata-se também, no entanto, que os usuários compreendem a importância da corresponsabilidade na constante vigilância dos níveis pressóricos e glicêmicos, não deixando assim de praticar o autocuidado em casa, verificando frequentemente a pressão arterial e a glicemia. Além disso, o controle domiciliar evidencia nas falas o papel ativo do usuário no manejo de complicações agudas das doenças crônicas: 
A glicose verifico em casa, outro dia foi a 54 eu estava tremendo, aí coloquei um pouquinho de açúcar na boca, ela tinha baixado muito, mas aí logo melhorei. Mas quando ela está alta eu também sinto temores, eu vejo no aparelho aí me controlo (E4).

(...) tomo a insulina um pouco de manhã e um pouco à noite e a minha glicose sempre está nos dois dígitos, que é o importante. Na noite eu sei que a minha glicose está controlada, é a pior hora, se abaixar você morre. Se subir de manhã o aparelho bate lá 200 e poucos. Mas tomo remédio, tomo insulina e no outro dia já está normalizado e assim vamos vivendo (E2).

Destaca-se ainda na fala dos participantes, entre as atividades desempenhadas no grupo, a importância que eles atribuem às aulas semanais do exercício aeróbico denominado Zumba e da ginástica geral:

(...) o grupo representa uma série de coisas positivas, o grupo é dinâmico, e faz com que nós tenhamos uma vida mais dinâmica (E12).

O grupo daqui é tudo, estava aqui, parti para a zumba, parti para tudo! Aqui que botou a zumba e a ginástica (E6).

Eu fico rezando para chegar terça feira para ir para a zumba. Terça, quarta e quinta para mim são os melhores dias da semana (E5).

Ainda tem a ginástica, tem a zumba. A gente faz festinha, faz passeio, é tudo o que a nossa idade quer que aconteça (E2).

Os depoentes apresentaram o grupo como facilitador do autocuidado, na medida em que este atua melhorando o conhecimento sobre si mesmos, de seu estado de saúde e da doença, bem como as possibilidades de se cuidar no cotidiano. Contata-se que somente após o ingresso no grupo bem vivido que esses conhecimentos e conscientização sobre o cuidado de si se efetivaram na vida do usuário:

A minha mãe era diabética e os parentes todos por parte da minha mãe. Sobre alimentação eu aprendi não comer certas coisas por conta da pressão alta, aí eu disse: ah é mesmo? Então vou ter que mudar (E9).

Eu sabia que meu pai era diabético, mas eu não tinha noção do que era a diabetes. Depois então que eu vim para cá que começou a falar, que aqui eles explicam, eles falam muito das enfermidades, dão muito conselho, como a gente tem que fazer, sendo que até então eu não tinha diabetes. Então nesse período que eu descobri que eu tenho diabetes (E10).

\section{DISCUSSÃO}

A análise do perfil sociodemográfico dos entrevistados evidenciou uma maioria do sexo feminino. A literatura destaca o predomínio de mulheres quando se avalia o perfil epidemiológico de DCNT, decorrente possivelmente do fato de dessa população procurar o serviço de saúde tendo em vista sua maior percepção sobre o processo saúde/doença, maior tendência para o autocuidado e busca de auxílio médico. No que respeita à faixa etária observada e a prevalência de pacientes com 60 anos, deve-se considerar o processo de transição demográfica pelo qual o Brasil vem passando, com acentuado envelhecimento populacional e aumento de DCNT. O processo de envelhecimento fisiológico que acomete o paciente idoso contribui para a ocorrência de enfermidades crônicas (SOUSA et al., 2019).

Outro ponto de destaque é a predominância de pardos e negros, e ainda que essa análise seja limitada por haver diferentes classificações para etnia/raça, o que dificulta a comparação e discussão dos dados, a literatura aponta relação existente entre pior status socioeconômico com negros e pardos, o que reflete em piores condições de saúde desta parcela da população (SILVA et al., 2018).

O grupo educativo voltado a clientes hipertensos e diabéticos é um espaço de acolhimento e incentivo na APS, que mostrou desempenhar, segundo os participantes desse estudo, papel fundamental na socialização, desse modo estabelecendo boas interações, vivências lúdicas, sociabilidade e superação de adversidades individuais, empoderando o sujeito e levando-o a refletir sobre a mudança na sua forma de vida.

O apoio psicossocial que o grupo fornece ao indivíduo é evidenciado na literatura que destaca a redução do medo e ansiedade pelo participante ao conviver com pessoas com condições semelhantes a sua, como também a aceitação facilitada de sua condição crônica e a promoção da qualidade de vida. $O$ grupo constrói uma rede de apoio mútuo, fazendo os membros sentirem-se amparados, por haver pessoas que compreendem suas necessidades, além de proporcionar estabilidade emocional (MELO, 2016).

As ações desenvolvidas no grupo que primem pela socialização e recreação promovem a autoestima e o aprendizado do indivíduo por meio das relações sociais construídas, além de oportunizarem descontração, alegria, compartilhamento de momentos de lazer e na potencialização dos talentos de todos os envolvidos (SILVA, 2018). 
Para muitos pacientes, o convívio com uma doença crônica acarreta a presença de sentimentos negativos, entre eles frustração, decepção, nervosismo e impotência. A oportunidade que a estratégia em grupo oferece a estes indivíduos ao compartilharem as experiências e sentimentos vivenciados revela-se nas falas analisadas como oportunidade de reelaborar estes sentimentos (VIEIRA; CECILIO; TORRRES, 2017).

A narrativa dos integrantes da presente pesquisa enfatiza que o ato de participar do grupo está relacionado a obter facilidades de acesso ao serviço de saúde. Existe nessa relação uma possibilidade de ultrapassar burocracias relativas à organização e funcionamento do serviço de saúde, representadas por senhas, filas, agendamentos e formulários. Contrariamente à ideia de "espaço educativo" voltado para a adesão ao tratamento, os participantes podem compreender o grupo como espaço formulador e mantenedor de redes de relações (MELO; CAMPOS, 2014; RETICENA et al., 2015).

A prática de grupo, contudo, muitas vezes acaba sendo reduzida na concepção do participante exclusivamente a um caráter clientelista e assistencialista, focada na realização de procedimentos. Ressalta-se que embora sendo relevantes, essas ações não constituem a finalidade dos grupos de educação em saúde, mas sim construir participação e corresponsabilidades dos usuários nos serviços de saúde, como preconiza o Sistema único de Saúde. Dessa forma, é necessário que haja equilíbrio, para que o grupo por um lado atenda as necessidades da dinâmica do atendimento em saúde, mas que por outro não perca sua essência educativa e empoderativa (OLIVEIRA et al., 2016).

Os usuários atribuem ainda a sua participação no grupo como fonte de suporte para manterem as práticas de autocuidado. Os encontros mostram-se relevantes para auxiliar os participantes nas tomadas de decisão, uma vez que afirmaram ter a tendência em desenvolver ações necessárias para o autocuidado (VIEIRA; CECILIO; TORRRES, 2017).

Os discursos dos entrevistados referentes à adoção de hábitos alimentares adequados é um dos aprendizados adquiridos no grupo. Nesse sentido, a educação alimentar tem a capacidade de modificar positivamente inúmeras condições que se relacionam aos fatores de risco adicionais para as DCNTs. Estudos revelam que a aplicação de intervenções abrangendo atividades em grupo para hipertensos promoveu favoráveis alterações na dieta, havendo aumento do consumo de alimentos considerados protetores a saúde (MACHADO et al., 2016). Por conseguinte, a adoção de uma "dieta comedida" é bastante explícita, o que expressa o trabalho desempenhado no grupo no que respeita à mudança de hábitos alimentares, adequando a satisfação e as necessidades da pessoa.

A postura constatada na fala de alguns participantes referente à aceitação da doença e do tratamento e de novas maneiras de se cuidar é essencial para o manejo de várias condições de saúde. Ao compreender a sua doença crônica o usuário estabelece importante posição nas ações de controle e cuidado. O reconhecimento de ter uma doença crônica, e lidar com as limitações relacionadas a essa enfermidade, são relevantes para o autocuidado e o sucesso do tratamento (YOSHIDA; ANDRADE, 2016).

A noção de tranquilidade que emerge nas falas dos entrevistados quando explicitam o papel do grupo no controle pressórico demonstra que os participantes do grupo, em alguns momentos, projetam nos profissionais a responsabilidade do processo de tomadas de decisão no que se refere ao seu autocuidado, todavia deve-se atentar para a corresponsabilidade de ambos no processo de empoderamento (MELO; CAMPOS, 2014), dos valores de saúde e com a vitalidade.

Os depoimentos dos participantes da pesquisa revelam a corresponsabilidade e participação do usuário como sujeito ativo no tratamento e no cuidado da sua própria saúde. É necessário que a equipe de saúde motive o usuário a ser ativo, autônomo e participativo (SECCO; PARABONI; ARPINI, 2017).

As atividades físicas citadas pelos entrevistados, como grupos de caminhada e exercícios supervisionados, são parte da terapêutica não farmacológica que se mostra relevante na redução da pressão arterial e na regulação glicêmica, além de controle dos fatores de risco. Essas atividades podem ser reconhecidas como coadjuvantes à terapêutica medicamentosa e acompanhamento clínico e podem ser executadas com mais facilidade pelos profissionais de saúde (HORTENCIO et al., 2018).

Ao trabalhar com as orientações em grupo, os profissionais de saúde trabalham no sentido de romper as dificuldades de aquisição de novos conhecimentos dos participantes, transformando-o em conhecimento elaborado e participativo sobre a saúde, a doença crônica e suas formas de cuidado. Isto se explicita nas falas dos participantes que citam melhor compreensão de suas enfermidades e tratamento (SOUSA; MARTINS; PEREIRA, 2015).

O grupo educativo de DCNT deve garantir que a prática do autocuidado seja recebida como mensagem, compreendida e incorporada no cuidado cotidia- 
no do usuário. A mudança inicia-se a partir do ato de conhecer, mas somente será efetiva se passar pela reflexão crítica do indivíduo (SANTOS et al., 2018).

\section{CONCLUSÃO}

Constatou-se que as estratégias de cuidado no grupo educativo desenvolvidas pela equipe multiprofissional a clientes com DCNT constituem-se em importante recurso de abordagem voltado a essa clientela na atenção primária à saúde.

Entre as concepções dos usuários no que se refere às atividades em grupo, repercutindo no cuidado com a vida, destaca-se a promoção de vivências, que é evidenciada por falas que contemplam bons sentimentos, melhora do humor e da socialização e reelaboração psicológica dos problemas cotidianos, um novo olhar e cuidados específicos diante da condição crônica.

As práticas de autocuidado emergiram como fruto das atividades em grupo, favorecendo um estilo de vida mais saudável, melhora da autoestima e de maior engajamento social.

Destarte, as narrativas dos usuários não enfatizam práticas restritivas, mas sim atividades que visem à emancipação de possibilidades do cuidado com a vida, evitando complicações da hipertensão arterial e Diabetes Mellitus. Amplia-se, desse modo, a percepção de novas formas de cuidado, que vão além da doença e tratamento, tal como o gosto de viver e a buscar atividades que geram satisfação e ao mesmo tempo o bem-estar com o corpo e movimento.

A atividade de grupo gera maior aproximação do usuário com o sistema de saúde, como resultado da reflexão que o grupo constrói com o usuário acerca da importância do acompanhamento contínuo da saúde, bem como pela obtenção facilitada da assistência profissional e diagnóstica fornecida aos membros do grupo pela equipe de saúde.

O grupo exerce, portanto, um papel relevante no cuidado com a vida dos usuários, abarcando práticas peculiares do cuidado de enfermagem e de saúde, os cuidados promocionais, novas formas de viver e de se expressar, buscando estimular o desejo de viver e conviver em grupo. Enfim, o grupo apresenta repercussões relevantes na ampliação e na emancipação no cuidado com a vida, que se exerce de modo dialogado e interativo em uma atividade de educação em saúde.

Embora o grupo estudado tenha um caráter multiprofissional, ele é organizado também por enfermeiros que desenvolvem suas atividades de orientação de cuidados articulados com outros profissionais, de modo que esse estudo pode contribuir para a avaliação e intervenção participativa da enfermagem em grupo.

Os limites desse estudo restringiram-se às concepções dos usuários e a um grupo restrito a um cenário, segundo a abordagem qualitativa que ao mesmo tempo que contribui, instiga a ampliação de futuros estudos.

\section{REFERÊNCIAS}

ARANTES, R. K. M. et al. Educação que produz saúde: atuação da enfermagem em grupo de hipertensos. Revista de Enfermagem da UFSM, Santa Maria, v. 5, n. 2, p. 213-223, 2015.

BARDIN, L. Análise de conteúdo. São Paulo: Edições 70, 2011. 229 p.

BRASIL. Ministério da Saúde. Secretaria de Atenção à Saúde. Departamento de Atenção Básica. Política Nacional de Atenção Básica. Brasília, DF: MS, 2012.

COLLIÉRE, M. F. Cuidar: a primeira arte da vida. 2. ed. Loures: Lusociência, 2003. 440 p.

COLLIÈRE, M. F. Promover a vida: da prática das mulheres de virtude aos cuidados de enfermagem. Lisboa: Lidel, 1999. 385 p.

DUARTE, G. C. et al. Práticas de promoção à saúde e prevenção de agravos no grupo Hiperdia. Revista Espaço Ciência \& Saúde, Cruz Alta, v. 3, p. 59-69, 2015.

GERHARDT, P. C. et al. Tendência das internações por diabetes mellitus e hipertensão arterial sistêmica em idosos. Cogitare Enfermagem, Curitiba, v. 21, n. 4, p. 1-10, 2016.

HORTENCIO, M. N. S. et al. Efeitos de exercícios físicos sobre fatores de risco cardiovascular em idosos hipertensos. Rev. Bras. Promoç. Saúde, Fortaleza, v. 31, n. 2, p. 1-9, abr./ jun. 2018.

MACHADO, J. C. et al. Análise de três estratégias de educação em saúde para portadores de hipertensão arterial. Ciênc. Saúde Coletiva [on-line], Rio de Janeiro, v. 21, n. 2, p. 611-620, 2016.

MADEIRA, F. B. et al. Estilos de vida, habitus e promoção da saúde: algumas aproximações. Saude Soc., São Paulo, v. 27, n. 1, p. 106-115, 2018.

MELO, L. P. É como uma família: significados atribuídos a grupos de educação em saúde sobre diabetes por profissionais da saúde. Ciênc. Saúde Coletiva, Rio de Janeiro, v. 21, n. 8, p. 2.497-2.506, 2016.

MELO, L. P.; CAMPOS, E. A. "O grupo facilita tudo": significados atribuídos por pacientes portadores de diabetes mellitus tipo 2 a grupos de educação em saúde. Rev. Latino-Am. Enfermagem. Ribeirão Preto, v. 22, n. 6, p. 980-987, 2014.

OLIVEIRA, D. M. et al. Concepções e práticas de educação em saúde: perspectiva de enfermeiros da estratégia saúde da família. Rev. Enferm. Ufpe on-line, Recife, v. 10, n. 11, p. 3.901-3.910, nov., 2016. 
OLIVEIRA, F. A. et al. Atividades de educação em saúde realizadas com grupo de idosas para promoção do autocuidado em saúde. Extensio: R. Eletr. de Extensão, Florianópolis, v. 15, n. 28, p. 137-150, 2018.

OREM, D. Nursing: concepts of practice. 6. ed. St. Louis (US): Mosby, 2001. 542 p.

RETICENA K. O. et al. Percepção de idosos acerca das atividades desenvolvidas no Hiperdia. Rev. Min. Enferm., Belo Horizonte, v. 19, n. 2, p. 107-113, 2015.

SANTOS, J. C. et al. Comparação das estratégias de educação em grupo e visita domiciliar em diabetes mellitus tipo 2: ensaio clínico. Rev. Latino-Am. Enfermagem. Ribeirão Preto, v. 25, e2979, p. 1-11, 2017.

SECCO, A. C.; PARABONI, P.; ARPINI, D. M. Os Grupos como dispositivo de cuidado na $A B$ para o trabalho com pacientes portadores de diabetes e hipertensão. Mudanças - Psicologia da Saúde, São Bernardo do Campo, v. 25, n. 1, p. 9-15, 2017.

SILVA, R. D. Grupo de convivência: percepção dos idosos em uma unidade básica de saúde. Revista Família, Ciclos de Vida e Saúde no Contexto Social, Uberaba, v. 6, n. 3, p. 432438, 2018.

SILVA, A. et al. Iniquidades raciais e envelhecimento: análise da coorte 2010 do Estudo Saúde, Bem-Estar e Envelhecimento (SABE). Rev. Bras. Epidemiol., São Paulo, v. 21, supl. 2, e180004, 2018.

SOUSA, M. R. M. G. C. S.; MARTINS, T.; PEREIRA, F. O refletir das práticas dos enfermeiros na abordagem à pessoa com doença crónica. Revista de Enfermagem Referência, Coimbra, s. IV, n. 6, p. 55-63, 2015.

SOUSA, N. A. et al. Fatores de risco e complicações em diabéticos/hipertensos cadastrados no hiperdia. Sanare, Sobral, v. 18, n. 1, p. 31-39, 2019.

STREHLOW, B. R. et al. Percepção dos usuários sobre os grupos de educação em saúde do pet-vigilância em saúde. J. Res.: Fundam. Care. on-line, Rio de Janeiro, v. 8, n. 2, p. 4.243-4.254, 2016.

VIEIRA, G. L. C.; CECILIO, S. G.; TORRES, H.C. A percepção dos usuários com diabetes sobre a estratégia de educação em grupos na promoção do autocuidado. Esc. Anna Nery, Rio de Janeiro, v. 1, n. 21, p. 1-6, 2017.

YOSHIDA, V. C.; ANDRADE, M. G. G. O cuidado à saúde na perspectiva de trabalhadores homens portadores de doenças crônicas. Interface - Comunicação, Saúde, Educação, Botucatu, v. 20, n. 58, p. 597-610, 2016. 